\title{
Precision mapping of boundaries of flood plain river basins using high-resolution satellite imagery: A case study of the Varuna river basin in Uttar Pradesh, India
}

\author{
Mallikarjun Mishra*@, Vikas Dugesar, K n Prudhviraju, Shyam Babu Patel \\ and KshitiJ Mohan \\ Department of Geography, Institute of Science, Banaras Hindu University, Varanasi 221 005, India. \\ ${ }^{*}$ Corresponding author.e-mail: mallikarjungeobhu2016@gmail.com
}

MS received 8 February 2018; revised 31 August 2018; accepted 23 September 2018; published online 6 April 2019

Accurate demarcation of river basin boundaries is an important input for any programme connected with watershed management. In the present study, the boundary of the Varuna river basin is automatically derived using coarse- and medium-resolution digital elevation models (DEMs) of SRTM-30 m, ASTER$30 \mathrm{~m}$, Cartosat-30 m, ALOS Palsar-12.5 m and Cartosat-10 m as well as manually through on-screen digitisation from a very high-resolution $1 \mathrm{~m} \times 1 \mathrm{~m}$ remote sensing data available as Google Earth image. The study demonstrated the efficacy of on-screen digitisation from high-resolution Google Earth image supported by detailed field observations in the precision mapping of the place of origin of the Varuna River, its stream network and basin boundary when compared to the maps generated through automatic methods using DEMs of various resolutions. The Varuna river system takes its headwaters from the areas surrounding Umran and Dain 'tals' (shallow, large depressions/basins) but not from the west of Mau Aima town as has been previously reported.

Keywords. Varuna river; origin; catchment; DEMs; Google Earth image.

\section{Introduction}

Drainage networks are the basis of watershed delineation, an essential component in hydrological modelling, biogeochemical applications and resource management plans (Yan et al. 2018). With the advent of remotely sensed digital elevation models (DEMs), there has been a spurt in studies on DEM-based drainage network extraction algorithms (Purinton and Bookhagen 2017; Yan et al. 2018). Many factors such as the scale, DEM quality, physical characteristics of the river basin and the algorithms used influence the accuracy of drainage networks that are derived from
DEMs (Martins et al. 2017). However, conventional DEM processing methods may not yield realistic drainage networks, especially in plain river drainage basins (Lai et al. 2016). Moreover, most of the freely available DEMs on the internet space are coarse to medium resolution and hence are fraught with some limitations in their spatial accuracies (Das et al. 2016). The limitations in data accuracy in the satellite data-derived DEMs are due to three groups of errors: depending on the system parameters during data acquisition, rawdata processing steps and the degree of influence of vegetation and land cover (Elkhrachy 2017). Therefore, the basin boundary derivation through 
automated methods from coarse to medium DEMs in plain area with low relief cannot has comparable accuracy with manually derived drainage networks and basin boundaries on very highresolution two-dimensional remote sensing data (Potere 2008; Goudie 2013; Prudhvi Raju et al. 2014a,b). Although high-resolution aerial stereo photographs and LiDAR imagery are desirable for accurate mapping of drainage networks, they are highly cost intensive and not available, especially in the Indian context. Under these circumstances, the high-resolution satellite images that are freely available on Google Earth are a better option for deriving drainage networks and delineating basin boundaries of river basins, especially in the floodplain regions. The objective of the present study is to demonstrate the relative merits of the highresolution satellite data ubiquitously available on Google Earth when compared to the coarse- to medium-resolution satellite-derived DEMs for precision mapping of the drainage networks and basin boundaries, especially of low-relief floodplain rivers by taking the Varuna river basin as a case study.

Of late, National Ganga River Basin Authority (NGRBA) in India has initiated many programmes to implement the 'Ganga River Basin: Environment Management Plan (GRB EMP)' for effective abatement of pollution and conservation of the river Ganga (GBP Report 2010). While dealing with the river Ganga one has to deal with its tributaries too. The river Ganga has many large tributaries - Yamuna, Ramganga, Ghaghra, Gandak, Kosi, Son, etc. - of mountainous/hilly origin and also has many medium to small tributaries originating within and flowing through its floodplain. It is these floodplain tributaries that do not get flushed of pollutants during the non-rainy season and are degrading. This is one of the reasons why the floodplain tributaries of the river Ganga need attention and need to be rejuvenated. The Varuna river is one such floodplain tributary of the river Ganga (figure 1). Figure 2 shows the general relief of the Varuna river basin. The Varuna river originates at an elevation of $112 \mathrm{~m}$ and after flowing through a length about $225 \mathrm{~km}$ meets the river Ganga just northeast of Varanasi city where the ground elevation is $65 \mathrm{~m}$. Therefore, the river flows over an extremely gentle gradient of $0.21 \mathrm{~m}$ per $1 \mathrm{~km}$. With a catchment area of about $3141 \mathrm{~km}^{2}$ the Varuna river is one of the mediumsized tributaries of the Ganga river. The Varuna Corridor Project of the Government of Uttar Pradesh is one example wherein its rejuvenation is one of the objectives. A number of studies are being carried out on the many floodplain tributaries of the river Ganga for the purpose of rejuvenating the rivers as well as to work out the surface water potentials (Vaidyanadhan 2014; Prudhvi Raju et al. 2014a, b), to take flood mitigation measures (Sinha and Jain 1998) and to effectively address the pollution problems (Raju et al. 2009; Singh et al. 2013).

The entire area of the Varuna river basin is composed of unconsolidated flood alluvium of recent age (Raju et al. 2009). Although the plain appears as rather a flat alluvial plain (Singh 1996), it shows up sandy surfaces at relatively higher elevations (higher level floodplain) and clayey surfaces (lower level floodplain) at lower elevations. This plain, like the rest of the floodplain of the Ganga river, is dotted with numerous tals (shallow, large depressions/basins), ponds, meander scrolls and oxbow lakes. With around $800 \mathrm{~mm}$ of rainfall in the region and with a generalised run-off coefficient of 0.30 (for floodplains - CPWD 2002; Gwinnet County Georgia 2006; ODOT Hydraulics Manual 2011) and with an area of $3141 \mathrm{~km}^{2}$, the generalised potential water discharge of the basin is around 75 MCM.

Floodplain rivers with very low total and relative relief present a problem while deriving boundaries from DEMs, especially because the derivatives from DEMs are dependent not only on horizontal and vertical resolutions but also on some input parameters such as flow accumulation, pour point, flow length, stream length, basin, etc. If these parameters change, boundaries and drainage network will change. Further, some complications arise due to engineering constructions such as canals, roads and other embankments with comparatively higher relative relief from the local ground surface. In the present study, a substantial length of the basin boundary falls over canals and roads (table 1). The best way to overcome the problem of topography beset with such features is the visual demarcation of boundaries using very-high-resolution two-dimensional remote sensing data or to use 1-2 $\mathrm{m}$ high-resolution DEMs or large-scale stereo aerial photos. The central and state governments and several non-governmental organisations are making efforts to rejuvenate this floodplain tributary of the Ganga to mitigate the flood problem, especially in its lower reaches near Varanasi city and to reduce/control pollution into the Ganga. At present, the Varuna river like many other floodplain tributaries of the river Ganga is 

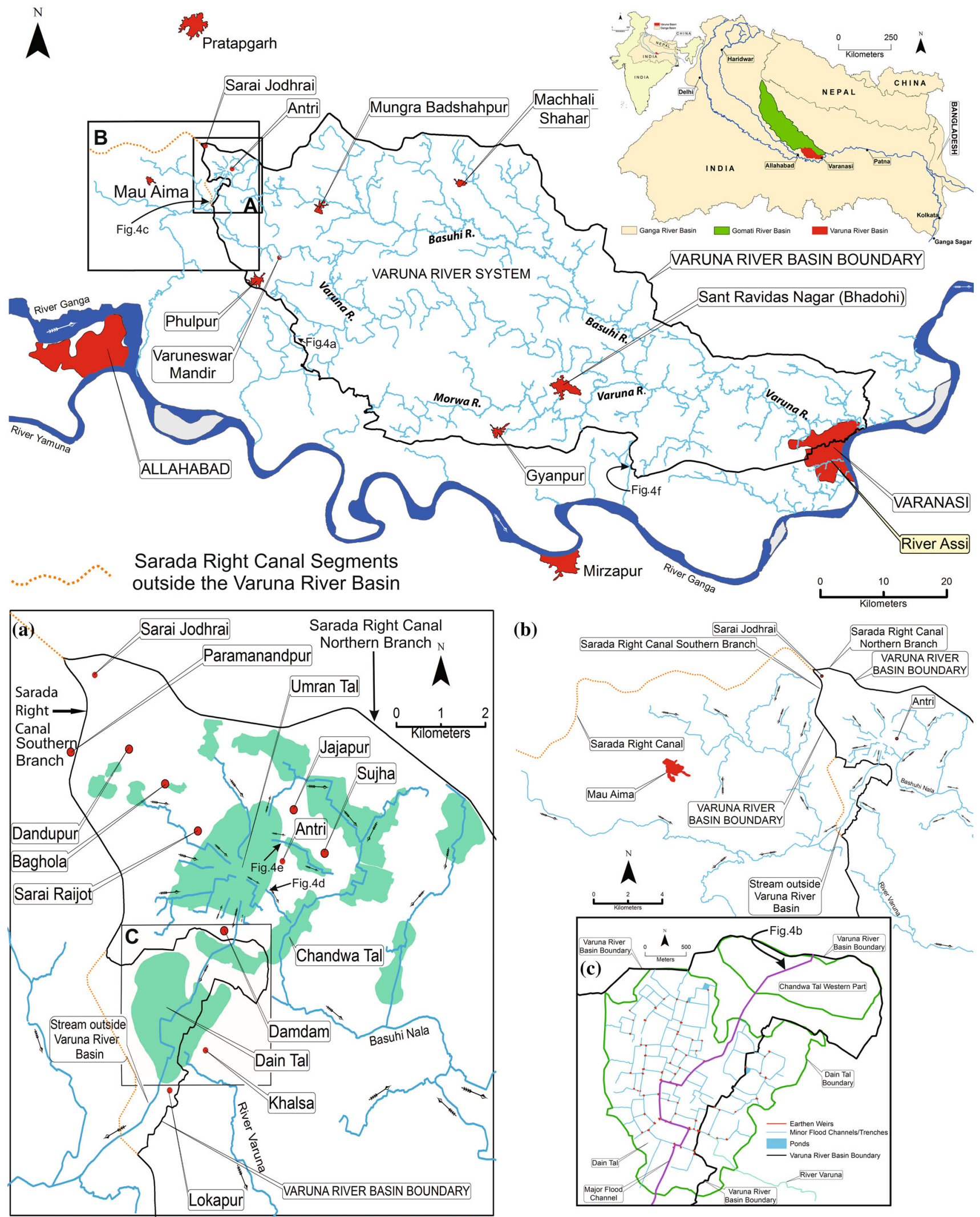

Figure 1. Varuna river system and its catchment. Location map showing the Varuna river basin within India and the Ganga river basin (inset); (a) Varuna river upper reaches, its basin boundary and surroundings showing tals and streams; (b) Varuna river headwater streams, its basin boundary and some streams outside on the western part of the Varuna upper reaches; and (c) Dain Tal showing minor flood channel/trench network with weirs. 


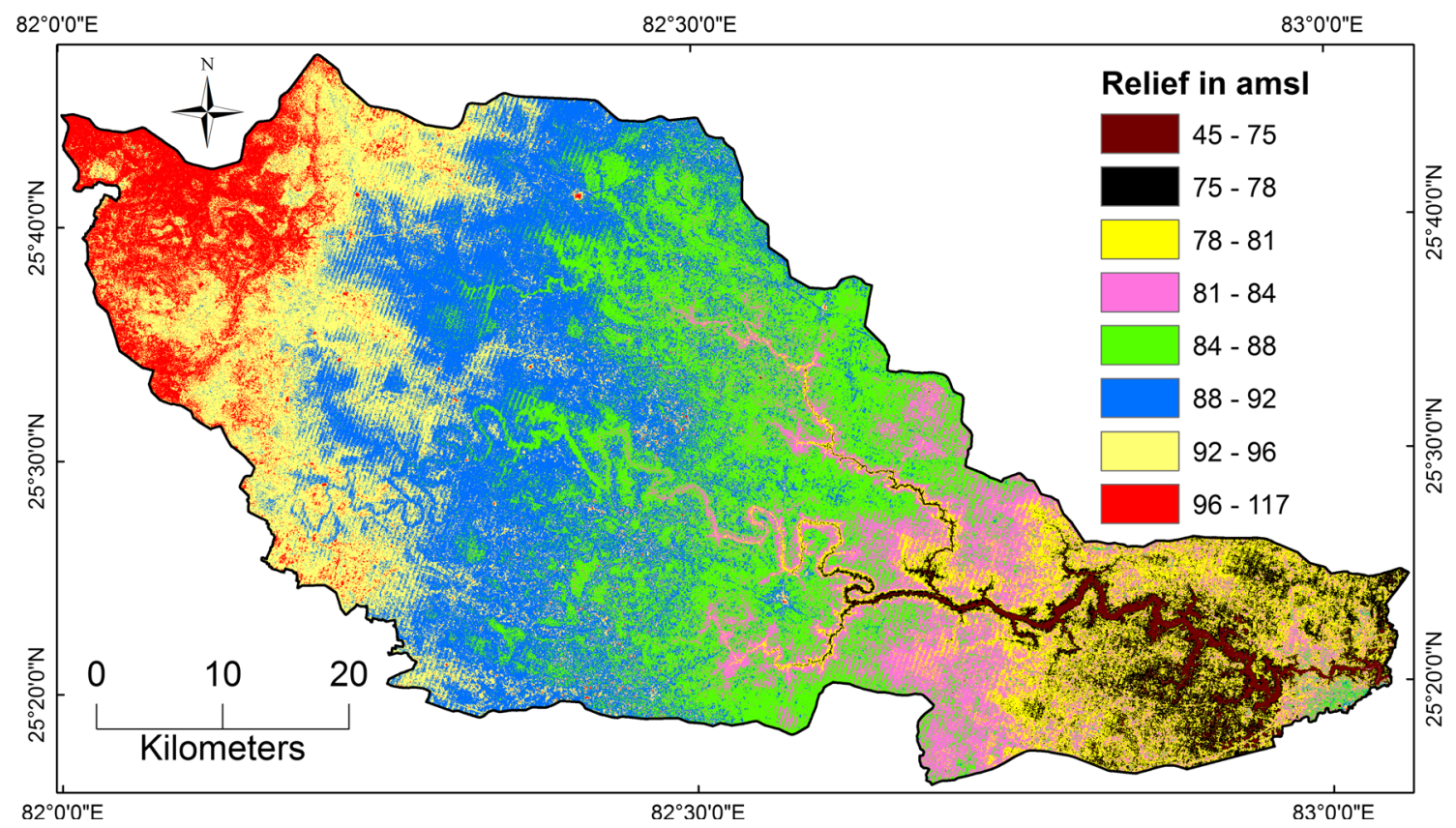

Figure 2. DEM (Cartosat $10 \mathrm{~m}$ ) showing elevation classes in the Varuna river basin.

Table 1. Divisions (in $\mathrm{km} / \%$ ) of the Varuna river basin perimeter.

\begin{tabular}{lccc}
\hline $\begin{array}{l}\text { Total length } \\
\text { of perimeter }\end{array}$ & $\begin{array}{c}\text { Over natural } \\
\text { surface }\end{array}$ & $\begin{array}{c}\text { Along } \\
\text { roads }\end{array}$ & $\begin{array}{c}\text { Along } \\
\text { canals }\end{array}$ \\
\hline $335 / 100$ & $43 / 12.83$ & $56 / 16.71$ & $236 / 70.44$ \\
\hline
\end{tabular}

not what it used to be - the channel width and depth at places has shrunk because of bed siltation, overwash from the bank, weed and tree growth, encroachments, etc., because of which flood problem has exacerbated. Although this area receives an average annual rainfall of $800 \mathrm{~mm}$, the water flow is not sustained beyond December. After December, the few pools in its bed here and there dry up completely by March. Currently, some stretches of the Varuna channel banks are being lined by a series of steps by removing encroachments and especially at the places where there are important temples. The River Basin Atlas of India (2012), available at the website http://www.indian.wris. nrsc.gov.in, contains boundaries of 25 large river basins and sub-basins of India derived from SRTM DEM (resolution not mentioned). The Varuna river basin boundary, i.e., the present study area, is not shown in the Atlas. Needless to mention, the accurate mapping of drainage networks (especially the headwater point of the main river) and watershed boundaries is imperative for estimating the basin area which has a bearing on the calculation of water discharges, sediment loads and flood hydrographs.
Prakash et al. (2016) used the SRTM DEM data (resolutions are not stated in the paper) and generated the Varuna stream network and its water divide through automatic methods and reported that the Varuna river 'emanates from near Mau Aima in Allahabad district, Uttar Pradesh' and their (Prakash et al. 2016) figure (in figure 3) shows the perimeter of the Varuna basin extending to about $17 \mathrm{~km}$ general west from the Mau Aima town. Locals (from Mailhan, Phulpur and Mungra Badshahpur towns in east Uttar Pradesh) claim that it (the Varuna) just starts a few kilometres from here indicating towards general west'.

\section{Data and methodology}

The present study is mainly based on manual onscreen mapping/digitisation of the river system and catchment boundary from Google Earth image under very high magnification and field observations at the headwaters of the Varuna river system. Google Earth image is composed of very 


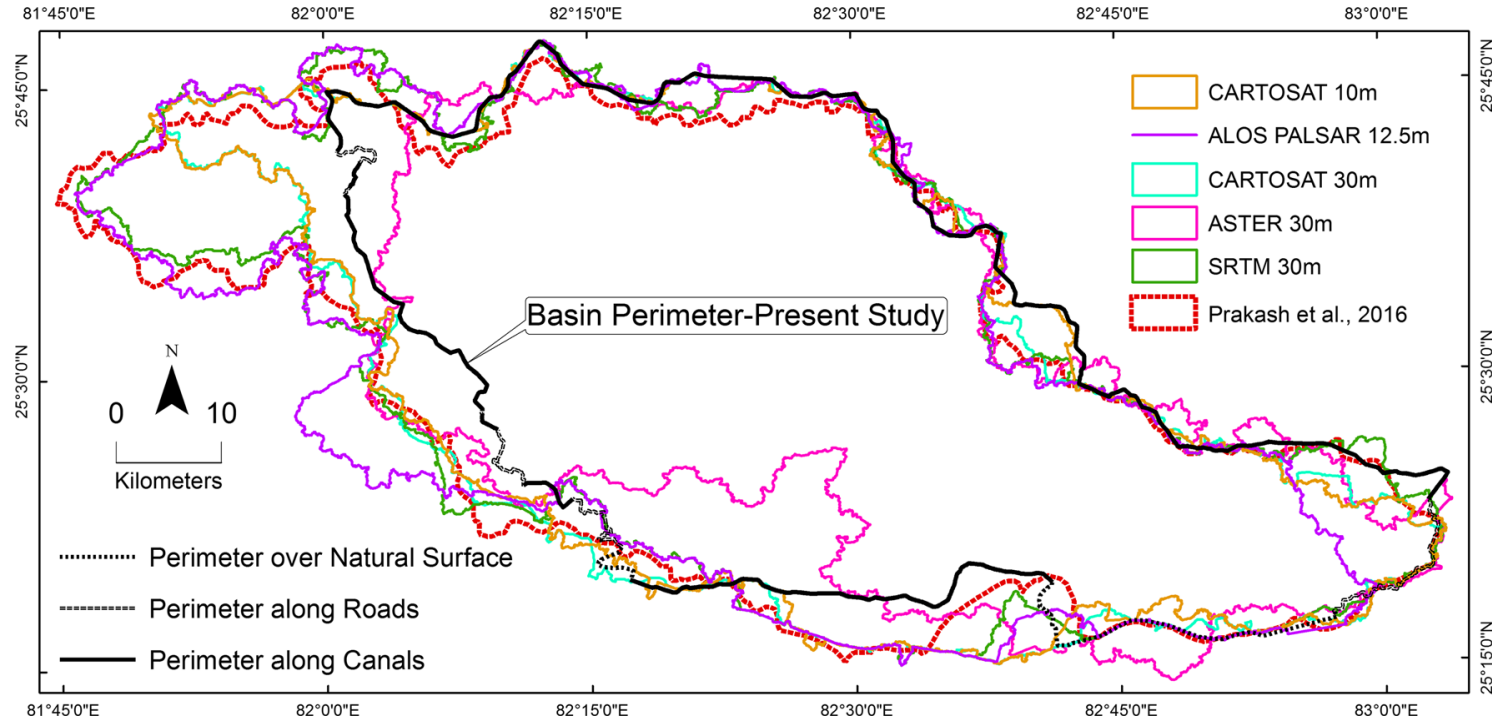

Figure 3. Varuna river basin boundary derived from DEMs of different resolutions and that of the present study.

Table 2. Varuna river basin area $\left(\mathrm{km}^{2}\right)$ from different DEMs.

\begin{tabular}{lccc}
\hline DEMs & $\begin{array}{c}\text { Basin area } \\
\text { from DEMs }\end{array}$ & $\begin{array}{c}\text { Basin area } \\
\text { present study }\end{array}$ & Difference \\
\hline CARTOSAT $10 \mathrm{~m}$ & 3474 & 3141 & +333 \\
ALOS PALSAR 12.5 m & 3720 & +579 \\
CARTOSAT 30 m & 3502 & +361 \\
ASTER 30 m & 2923 & -218 \\
SRTM 30 m & 3683 & +542 \\
Prakash et al. (2016) SRTM & 3583 & +442 \\
\hline
\end{tabular}

high-resolution remote sensing data from IKONOS, QuickBird, GeoEye, WorldView, etc., satellites (https://www.google.com/intl/en_in/earth/). The data used in the present study is of March 2017 of WorldView 2, which records the data at the 11-bit radiometric range with $0.46 \mathrm{~m}$ resolution in the panchromatic band (450-800 $\mathrm{nm}$ ) and with $1.85 \mathrm{~m}$ resolution for multi-spectral bands (https:// www.spaceimagingme.com/downloads/.../WorldV iew2-DS-WV2-Web.pdf). Normally, the data displayed on Google Earth image is a pan-sharpened data resampled to $1 \times 1 \mathrm{~m}$ resolution. Although the geolocation accuracy (comparison between the surveyed ground control point and the corresponding location in remote sensing data) claimed by the Google Earth image is $<3.5 \mathrm{~m}$, it can quite often go up to sub-metre level (Potere 2008; Goudie 2013; Prudhvi Raju et al. 2014a, b). In the present study, we have extracted the Varuna basin boundary through automated method from coarse- to medium-resolution SRTM DEM-30 m, ASTER$30 \mathrm{~m}$, Cartosat DEM-30 m, ALOS Palsar-12.5 m and Cartosat DEM-10 m, and also through on-screen digitisation from the high-resolution Google Earth image. The basin boundaries and the area obtained from all the DEMs and that from the Google Earth image were compared (figure 3 and table 2). It is observed that the boundary derived from ASTER $30 \mathrm{~m}$ DEM is quite at odds from those derived from the other DEMs. It is basically because the ASTER $30 \mathrm{~m}$ data is not hydrologically corrected. This boundary is given especially to prove a point that the automatically derived boundaries from DEMs depend on several corrections and factors like fill, sink, etc. On the other hand, Google Earth, apart from providing high-resolution images for detailed mapping, also offers tools to digitise lines, polygons and points straight over the image using which major streams and basin boundaries were digitised into Keyhole Markup Language Zipped files which are actually compressed version of Keyhole Markup Language files. These files were then opened in Global Mapper software and were given projection and saved as shape (.shp) files. The .shp files were then processed and composed in ArcGIS 

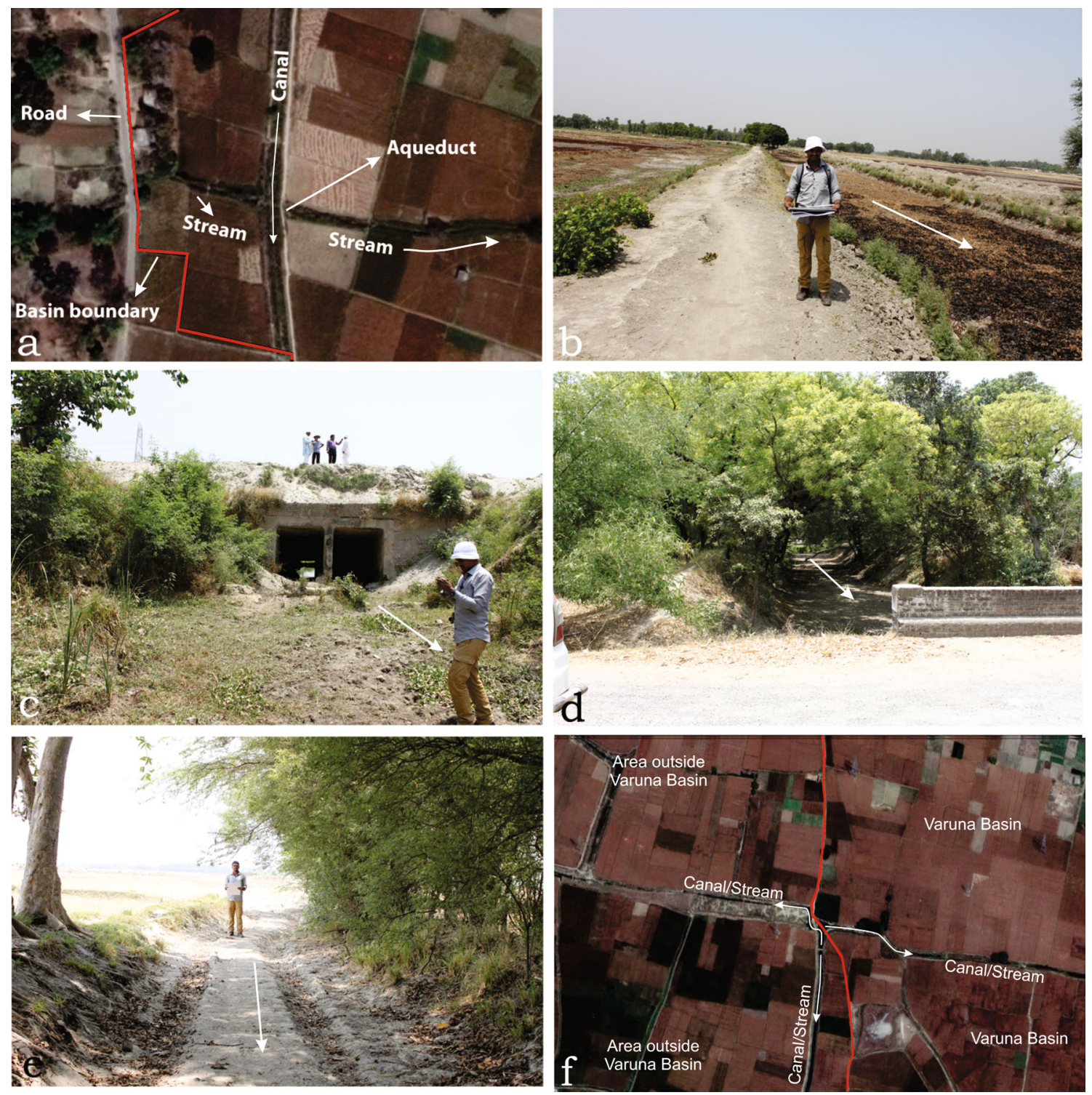

Figure 4. (a) Google Earth image showing stream passing from under the canal into the Varuna basin through an aqueduct; (b) deep excavated channel from Umran tal going into Dain tal and ultimately going through aqueduct (c) out of the Varuna basin; (c) An aqueduct (square openings below) passing under the canal (above); (d and e) Shallow channels going out of Umran tal south (d) and north (e) of Antri village; (f) Google Earth image showing basin boundary and a network of interlinked canals flowing in three different directions; locations of (a)-(f) are shown in figure 1.

software. A greater length of the Varuna river basin is bound by high and wide canals and roads (figures 1a, b and 3 and table 1). Through on-screen digitisation, it is possible to demarcate topographic features and medium-sized shallow drainage lines present within the floodplains of large rivers from $1 \times 1 \mathrm{~m}$ remote sensing data. Where there is doubt and depending upon the importance, the detailed field observations (figures $1 \mathrm{a}, \mathrm{b}$ and $4 \mathrm{a}-\mathrm{f}$ as indicated in figure 1) have been conducted for confirmation of digitised details in the present study.

\section{The place of origin of the Varuna river}

The Varuna river is labelled as Burna Nala in James Prinsep's map of 1822. Nala (pronounced ' $\mathrm{Na}$ ' as in naught and 'la' as in laughter) means a stream or a small stream. But in all the other maps (1911, 1914, 1925 and 1974) it is labelled as a river. In the Varuna river system, there are three major branches. Table 3 gives details of lengths of Varuna river and its major tributaries. In the extreme upstream region, the Varuna river catchment is bound by the branches of the Sarada right 
Table 3. Length of major tributaries of the Varuna river.

\begin{tabular}{lc}
\hline Tributaries/branches & Length in $\mathrm{km}$ \\
\hline Varuna river from its head to its confluence with the Ganga river & 225 \\
Varuna river from its head to its confluence with the Morwa tributary & 158 \\
Varuna river from its head to its confluence with the Basuhi tributary & 166 \\
Basuhi tributary from its head to its confluence with the Varuna river & 137 \\
Morwa tributary from its head to its confluence with the Varuna river & 71 \\
\hline
\end{tabular}

canal. The Sarada right canal branches out just at a distance of 600-700 m northwest of Sarai Jodhrai village (figure 1b). The northern branch of this canal (from near Sarai Jodhrai) forms the northern boundary between the Gomati and Varuna river systems; similarly, the southern branch too with exceptions here and there for a very long distance (figure 1a and b) forms the southern boundary between the Ganga channel catchment and Varuna river system. These canals being very high-level canals with 5-6 $\mathrm{m}$ high embankments on both sides clearly divide the waters between the Varuna river system and other stream systems on the other side. Although several distributaries of these two Sarada canal branches take off into the Varuna catchment area, the actual surface runoff from the other side of the Sarada canal branches does not flow into the Varuna river system. Care is taken through field checks and detailed image study to ascertain that areas outside these Sarada canals are not draining their waters through channels via aqueducts from under/above these two Sarada canal branches. In some cases, the presence of aqueducts is clearly visible in the Google Earth image data itself (figure 4a). Here (figure 4a) the waters from the west side of the Sarada right canal southern branch pass through an aqueduct from under the southern branch to enter into the Varuna river system.

Many scattered tals dot the Varuna catchment area like in the rest of the Ganga flood plain. These tals are large and shallow ponds/depressions/basins - 5-6 km across and along and 3-4 $\mathrm{m}$ deep) with floors flattening towards the centre. The tals collect runoff from the surrounding higher margins. In fact, the margins and floors of almost all the tals are occupied by agricultural fields. Dain tal locally called as Chhuchi tal is one such tal in the upper reaches of the Varuna catchment. Another tal called Umran tal $\left(3.72 \mathrm{~km}^{2}\right)$, which is a bit larger than Dain tal $\left(3.3 \mathrm{~km}^{2}\right)$, is situated just north of Dain tal. Moreover, several smallto medium-sized tals form an arc on the eastern side of this Umran tal; one of which is known as Chandwa tal (figure 1a). The headwaters of Varuna and Basuhi rivers flow into these tals. Several streams take off from Umran, Chandwa and the eastern arc of tals (referred to above) finally to make the Basuhi river the longest tributary of the Varuna river. The river Varuna starts from the eastern side of Dain tal (figure 1a). Here there is a need to mention that to drain the excess water of Umran, Chandwa and Dain tals to prevent flooding of surrounding agricultural fields within the tal and human habitations, a deep flood channel $(6 \mathrm{~m}$ from the top of the embankments to its bed) from near Damdam village (figure 1a and b) has been constructed. This flood channel starts from the southern part of Umran tal, passes through western part of Chandwa tal and enters the Dain tal and ultimately flows out of the Dain tal through an aqueduct (figures 1a and 4c) into another stream/river system (which flows general south to join the Ganga river just east of Allahabad) outside the Varuna basin. So, this way, the headwaters of the Varuna river system which collect into these tals are shared by another stream outside the Varuna basin. It is to be noted here that only after the water level reaches to a certain height in a part of the Umran tal, it enters into this flood channel and drains out of the Varuna basin passing through western part of Chandwa tal (south of Damdam). The water from the northeastern extension of Chandwa tal flows directly into the Varuna basin. But after the water level rises to a certain height the water from this NE extension of Chandwa tal enters into its western part. This is the reason why these two tals - Umran and NE extension of Chandwa - are included in the Varuna river basin.

It is to be noted here that the flood water channel referred to earlier taking off from Umran tal separates the Dain tal into two parts - the western part and eastern part separating its waters into the western component and eastern component (figure 1a and c). The Varuna river basin 
boundary passes through the eastern part along the left bank of another minor flood channel. To prevent flooding of the agricultural fields during the rainy season, a network of interconnected minor flood channels is constructed almost in every tal present in the basin. During rainy season waters from around the Dain tal get collected into the minor flood channels. These minor channels are interrupted by earthen weirs (figure 1c) at intervals in such a way that only after a stretch of a channel gets filled up to the level of cross weir, excess water spills/flows into the downstream or another segment and so on. Even at places where these minor flood channels meet the main flood channel, the waters do not enter the (major) flood channel directly but have to enter only as a spill/flow above the cross weirs at the confluences. This way the water entering the tals gets distributed into these minor flood channels and is retained within them. That is how only some excess water enters into the main flood channel. Thus, the agricultural fields within the tals are rarely flooded by the waters entering these tals. The excess water after the network of minor flood channels are filled flows out through either natural flow paths or deeply dug channels into the nearby stream/river systems. It is one such deeply dug channel that ultimately comes out of the eastern part of the Dain tal as the course of the Varuna river.

The basin boundary especially near Paramanandpur and around Sarai Jodhrai is clearly marked/ controlled by the presence of a high southern branch of Sarada right canal referred earlier (figure 1a and b). River/stream channels need not always extend right up to the basin boundaries. Normally, water flowing as overland flow from near the basin boundaries concentrates into a linear flow within the channels only after a certain distance from the boundaries. This is the reason why in some places the stream network is absent near the basin boundaries. A couple of channels going out of Umran tal to form into Basuhi Nala, which are not easily traceable from even the remote sensing data used in this study because of their smaller dimensions and the camouflage of tree canopy and built-up land, are confirmed only after visiting the field (figure 4d and e). In figure 1(b), the drainage on both sides of the southern branch of the Sarada right canal is clear enough to show that the area around Mau Aima on the west of this southern branch does not contribute water into the Varuna river system.

\section{Discussion and conclusion}

The present study based on our detailed field investigations distinctly demonstrates that the Varuna, especially at its head, does not extend beyond the eastern margin of Dain tal. Table 2 reveals the area variations of the Varuna river system obtained from DEMs of various coarse- to medium-resolution satellite data including what Prakash et al. (2016) reported vis-à-vis the area enclosed within the manually digitised and partly field verified boundary from very high-resolution remote sensing data which forms the mainstay of the present study. Table 3 reveals the lengths of the Varuna river and its major tributaries. Notably, the length of the Varuna river basin perimeter $(335 \mathrm{~km})$ and the extent of basin area $\left(3141 \mathrm{~km}^{2}\right)$ obtained from the precision mapping using the Google Earth images are relatively less when compared with those obtained from various DEM-derived data (table 2). This is mainly because of the fact that engineering constructions such as canal embankments and roads that control the drainage flow directions in the basin modify the basin dimensions in the recent decades. For instance, canal embankments align as much as $70.44 \%(236 \mathrm{~km})$ of the total $335-\mathrm{km}$-long perimeter of the Varuna basin boundary, while roads account for another $16.71 \%(56 \mathrm{~km})$ with only $12.83 \%(43 \mathrm{~km})$ of it representing the natural topography controlled line (table 1). Because of such features like canals and roads acting as artificial dykes, some areas which used to drain into the basin and some areas which used to drain out of the basin went out of and came inside the present Varuna river boundary, respectively. When topographic surfaces sloping in a certain direction are cut across by artificial dykes (in the form of roads and canals) forming basin boundaries, coarse resolution DEMs cannot account for such man-made modifications, especially when the dimensions of these dykes are smaller than the pixel resolutions and consequently the area on the other side of the dykes which is a continuation of the same topographic surface/slope gets added into the basin. This is the reason why the boundaries (of low alluvial plain rivers) automatically extracted from coarse-resolution DEMs cannot be accurate; and three of the DEMs shown in figure 3 got distended, covering additional areas from which waters, in fact, do not contribute to the Varuna basin because of the artificial dykes. Furthermore, there is another situation of certain segments of 
streams directed through aqueducts from under the canals into different stream system adjoining the Varuna river basin (figures $1 \mathrm{a}, \mathrm{b}$ and $4 \mathrm{c}$ ). In the Ganga floodplains in which the Varuna basin is situated, floods are a recurring problem. In order to mitigate this problem, several interlinked channels are constructed with locks and earthern/concrete weirs, and such interlinked channels pose a problem in demarcating the basin boundary. There is a peculiar case of such interlinked channel system in the Varuna basin (figure 4f) with water flowing in three different directions depending upon the elevations of weirs and water levels. Such details cannot be made out through remote sensing data; field visits or field mapping is the only solution in such situations. Mapping of river basin boundaries is very rarely taken up at such great detail and normally the basin boundaries are derived from contour maps. The Survey of India toposheets of plain areas like in the present case on a scale of 1:50,000 and even 1:25,000 with a contour interval of 20 and $10 \mathrm{~m}$, respectively, though can be relied upon to trace stream network, are not of any use to demarcate basin boundaries, especially in the case of floodplain rivers such as the Varuna basin.

Normally, in the plains, the headwater regions from where 3-4 streams originate show broad and almost flat topography. Moreover, in such areas with relief as low as 1-2 $\mathrm{m}$ over distances of 5-10 km along and across, to automatically derive boundaries from DEMs a vertical accuracy of $25-50 \mathrm{~cm}$ and a horizontal resolution of $50 \mathrm{~cm}-$ $1 \mathrm{~m}$ are required. DEMs with resolutions ranging from 90 to $10 \mathrm{~m}$ pixels with $30-8 \mathrm{~m}$ vertical accuracies are not fit enough to distinguish minor relief differences as low as $25-50 \mathrm{~cm}$. This is the main reason why in the headwater portions of the Varuna river system there are deviations in the boundaries from DEMs of coarse to medium resolutions and accuracies.

From this study, we may conclude that detailed interpretation of very high-resolution satellite imagery strengthened by intensive field investigations are essential for precision mapping of drainage networks and watershed boundaries, especially of low-relief floodplain rivers, instead of coarse- to medium-resolution DEMs for a realistic estimates on the stream lengths, gradients, basin areas, water yield and flood forecasting. The study also highlights the significance of Google Earth images for detailed mapping of surface features using the tools provided by Google.

\section{Acknowledgements}

The authors gratefully acknowledge Google Earth for the free availability of high-resolution satellite data and mapping tools. The authors are thankful to the anonymous reviewers and editor whose criticism has immensely helped improve this paper. They are thankful to the Head, Department of Geography, Institute of Science, Banaras Hindu University, for providing laboratory facilities to carry out this work. One of the authors (Mallikarjun Mishra) is thankful to the University Grants Commission, New Delhi, for awarding a Junior Research Fellowship.

\section{References}

Central Public Works Department (CPWD), Govt. of India 2002 Rainwater harvesting and conservation manual; Table No. 2, 14-15, accessed on 1 March 2014.

Das S, Patel P P and Sengupta S 2016 Evaluation of different digital elevation models for analyzing drainage morphometric parameters in the mountainous terrain: A case study of Supin-Upper Tons Basin, Indian Himalayas; Springerplus 5(1):1544, https://doi.org/10. 1186/s40064-016-3207-0.

Elkhrachy I 2017 Vertical accuracy assessment for SRTM and ASTER digital elevation models: A case study of Najran city, Saudi Arabia; Ain Shams Eng. J. 9(4) 1807-1817, https://doi.org/10.1016/j.asej.2017.01.007.

Goudie A 2013 Characterising the distribution and morphology of creeks and pans on salt marshes in England and Wales using Google Earth; Estuar. Coast. Shelf Sci. 129 112-123.

Gwinnet County Georgia 2006 Storm water systems and facilities installation, standards and specifications, Chapter 2 Hydrology; Table 2-5, 2B-9, http://www. gwinnettcounty.com/portal/gwinnett/Departments/ PublicUtilities/StormwaterManage-ment.

India-WRIS 2012 River basin atlas of India (in) Web GIS Water resources information system of India; http://www. india-wris.nrsc.gov.in, accessed on 18 June 2018.

Lai Z, Li S, Lv G, Pan Z and Fei G 2016 Watershed delineation using hydrographic features and a DEM in plain river network region; Hydrol. Process. 30(2) 276-288.

Martins T, Sousa I and Paz A R 2017 How to evaluate the quality of coarse-resolution DEM-derived drainage networks; Hydrol. Model. 31(19) 3379-3395.

ODOT Hydraulics Manual 2011 Hydrology - Appendix Table1, Chapter 7; ftp://ftp.odot.state.or.us/techserv/ GeoEnvironmental/Hydraulics/Hydro/Manuals_and Guidance/HDM\%202011/Chapter_07_2011/Chapter_07_ appendix_F/CHAPTER_07_appendix_F.pdf, accessed on 1 March 2014.

Potere D 2008 Horizontal positional accuracy of Google Earth's high-resolution imagery archive; Sensors $\mathbf{8 ( 1 2 )}$ 7973-7981. 
Prakash K, Singh S K and Shukla U K 2016 Morphometric changes of Varuna river basin, Varanasi district, Uttar Pradesh; J. Geomatics 10(1) 48-54.

Prudhvi Raju K N, Pandey M K and Sarkar S 2014a A note on boundaries in atlas maps; J. Geol. Soc. India 83 563566.

Prudhvi Raju K N, Sarkar S and Pandey M K 2014b Indus and Ganga river basins in India: Surface water potentials; In: Rejuvenation of surface water resources of India: Potential, problem and prospects (ed.) Vaidyanadhan R, J. Geol. Soc. India 3 43-53.

Purinton B and Bookhagen B 2017 Validation of digital elevation models (DEMs) and comparison of geomorphic metrics on the southern Central Andean Plateau; Earth Surf. Dyn. 5 211-237.

Raju N J, Ram P and Dey S 2009 Groundwater quality in lower Varuna river basin, Varanasi district, Uttar Pradesh; J. Geol. Soc. India 73 178-192.
Report Code: 001-GBP-IIT-GEN-DAT-01-Ver1 2010 River Ganga at a glance: Identification of issues and priority actions for restoration; pp. 1-19.

Singh I B 1996 Geological evolution of Ganga plain-An overview; J. Palaeontol. Soc. India 41 99-137.

Singh N L et al. 2013 Impact of river water on the ground water quality in Varanasi, Indian; J. Sci. Res. 4(1) 179 182.

Sinha R and Jain V 1998 Flood hazards of north Bihar rivers, Indo-Gangetic plains; Memoir 41, Geological Society of India, pp. 27-52.

Vaidyanadhan R 2014 Rejuvenation of surface water resources of India: Potential, problem and prospects; $J$. Geol. Soc. India Spec. Publ., No. 3, 109p.

Yan Y, Tang J and Pilesjo P 2018 A combined algorithm for automated drainage network extraction from digital elevation models; Hydrol. Process. 32(10) 1322 1333.

Corresponding editor: MARIPI DILEEP 